\title{
Monitoring to enhance modelling - A loads monitoring program for validation of catchment models
}

\author{
R.D.R. Turner ${ }^{\text {a }}$, R.A. Smith ${ }^{a}$, R.L. Huggins ${ }^{a}$, R.M. Wallace ${ }^{a}$, M.St.J Warne ${ }^{a}, \underline{\text { D.K. Waters }}{ }^{\text {b }}$ \\ ${ }^{a}$ Water Quality and Investigations, Environmental Monitoring and Assessment Science, Science Delivery, \\ Queensland Department of Science, Information Technology, Innovation and the Arts, Dutton Park \\ Queensland 4102, Australia \\ ${ }^{b}$ Queensland Department of Natural Resources and Mines, Toowoomba Queensland 4350, Australia \\ Email: Ryan.turner@gld.gov.au
}

\begin{abstract}
Diffuse pollutant loads discharged from rivers on the east coast of Queensland have caused a decline in water quality in the Great Barrier Reef (GBR) lagoon. The Reef Water Quality Protection Plan 2013 (Reef Plan) aims to halt and reverse the decline in water quality and enhance the resilience of the Reef. It also provides specific water quality and land management targets to be achieved in order to meet the Reef Plan goal.

Monitoring progress towards meeting Reef Plan targets is measured through the Paddock to Reef Integrated Monitoring, Modeling and Reporting Program (Paddock to Reef Program). The Paddock to Reef Program includes catchment scale water quality monitoring of pollutant loads (total suspended solids, nutrients and pesticides) entering the GBR lagoon. The catchment monitoring is conducted by the Great Barrier Reef Catchment Loads Monitoring Program (GBRCLMP). Monitoring data generated by GBRCLMP provides the point of truth to validate loads predicted by Source Catchment models. Loads generated by the model are used to report on progress towards water quality targets that are published in the annual Reef Plan Report Card.
\end{abstract}

The GBRCLMP calculates both annual and daily pollutant loads, based on monitoring data for 11 catchments that cover the majority of the Queensland east coast.

Over 8500 total suspended solid and nutrient samples have been collected and analysed since 1 July 2006 and more than 3000 pesticide samples have been collected and analysed since 1 July 2009. This has resulted in more than 250,000 discrete data points. This substantial data set allows for robust load calculations. The load calculations suggest that since 1 July 2006 approximately 80 per cent of the sediment loads delivered to the GBR lagoon originates from the two largest grazing catchments (the Burdekin and Fitzroy catchments). In addition, the Fitzroy catchment delivers over half the total monitored pesticide load to the GBR lagoon during the 5 year sampling period. Whereas the two regions with the highest proportion of sugarcane (the Mackay Whitsundays and Wet Tropics regions) deliver approximately one third with the Burdekin and Burnett Mary regions together delivering approximately a sixth. The other catchments deliver a very small proportion of the total pesticide load.

The loads monitoring program is a key component of the paddock to reef program. Whilst load based monitoring is expensive and challenging it is the fundamental point of truth for model validation.

This paper will summarise the GBRCLMP monitoring data collected since 1 July 2006; demonstrate the role of the GBRCLMP in model validation; outline some key improvements that have been made been; and describe the future direction and focus of the GBRCLMP which will continue to be based on the symbiotic relationship between modelling and monitoring.

Keywords: Great Barrier Reef, Loads, Monitoring, Validation, Water quality 


\section{INTRODUCTION}

Diffuse pollutant loads discharged from rivers on the east coast of Queensland are causing a decline in water quality in the Great Barrier Reef lagoon (Carroll et al., 2013; The State of Queensland 2013a). The Reef Water Quality Protection Plan 2013 (The State of Queensland 2013b) aim to halt and reverse the decline in water quality by improving land management practices.

Reef Plan is underpinned by pollutant reduction targets measured against a 2009 baseline (Kroon et al., 2010), that include a 20 per cent reduction in the anthropogenic load of total suspended solids by 2020; a 50 per cent reduction in anthropogenic load of nutrients (nitrogen and phosphorus) by 2018 ; and a 60 per cent decrease in photosystem II inhibitor herbicides by 2018 (DPC 2013). The majority of pollutant loads are generated during the wet season from runoff during flood conditions (Nicholls 1988; Eyre 1998). Water quality monitoring, during these events is essential to accurately calculate loads which discharge to the Great Barrier Reef.

Progress towards Reef Plan targets is measured through the Paddock to Reef Integrated Monitoring, Modelling and Reporting Program (Paddock to Reef Program) which is jointly funded by the Australian and Queensland governments. The Paddock to Reef Program includes catchment scale water quality monitoring of pollutant loads entering the Great Barrier Reef lagoon which is implemented through the Great Barrier Reef Catchment Loads Monitoring Program (Turner et al., 2012 and 2013).

The loads monitoring data from the GBRCLMP provides the point of truth to validate loads predicted by Source Catchment models, which are used to report annually on progress towards the Reef Plan targets, as part of the annual Reef Report Card.

Pollutant loads for the period between July 2006 and June 2012 have been calculated by the GBRCLMP at 31 sites across the following natural resource management regions and priority catchments:

- Cape York region - Normanby catchment

- Wet Tropics region - Barron, Johnstone, Tully and Herbert catchments

- Burdekin region - Burdekin and Haughton catchments

- Mackay-Whitsundays region - Plane, Pioneer and O'Connell catchments

- Fitzroy region - Fitzroy catchment and

- Burnett-Mary region - Burnett catchment.

These catchments were selected through a risk assessment process which identified these as posing the highest risk to the GBR (Shaw et al., 2011).

This paper will discuss the extent of sampling conducted in catchments that discharge into the GBR lagoon and the average normalised loads from the GBRCLMP from 1 July 2006 to 30 June 2012. In addition, it will summarise the programs load calculation approach. Furthermore it will outline improvements that have already been made to the program since its inception and show areas where monitoring data can be improved, including a new framework for selecting the most appropriate load estimation method for events based on sampling regimes. Finally, there will be discussion on the future direction and focus of the GBRCLMP that will continue to be based on the symbiotic relationship between modelling and monitoring where the monitoring data are essential to validate source catchment models and the models can help enhance monitoring.

\section{MONITORING METHODS}

Sampling occurs annually between 1 July and 30 June. Water samples were collected using methods outlined in the Environmental Protection (Water) Policy Monitoring and Sampling Manual (DERM 2009). Water quality samples presented in this paper were collected between 1 July 2006 and 30 June 2012. Manual grab sampling, automatic grab sampling, Van Dorn sampling and passive sampling techniques were all used.

\section{PROGRAM ACHIVEMENTS SINCE 2006}

Since 2006 the program has monitored a total of 31 individual sites (12 end-of-systems and 19 sub-catchment sites) for total suspended solids and nutrients, while eight end-of-systems and three sub-catchment sites have been monitored for photosystem II inhibitor pesticides since 2009. Over 8500 discrete total suspended solid and nutrient samples and more than 3000 pesticide samples have been collected and analysed. This has 


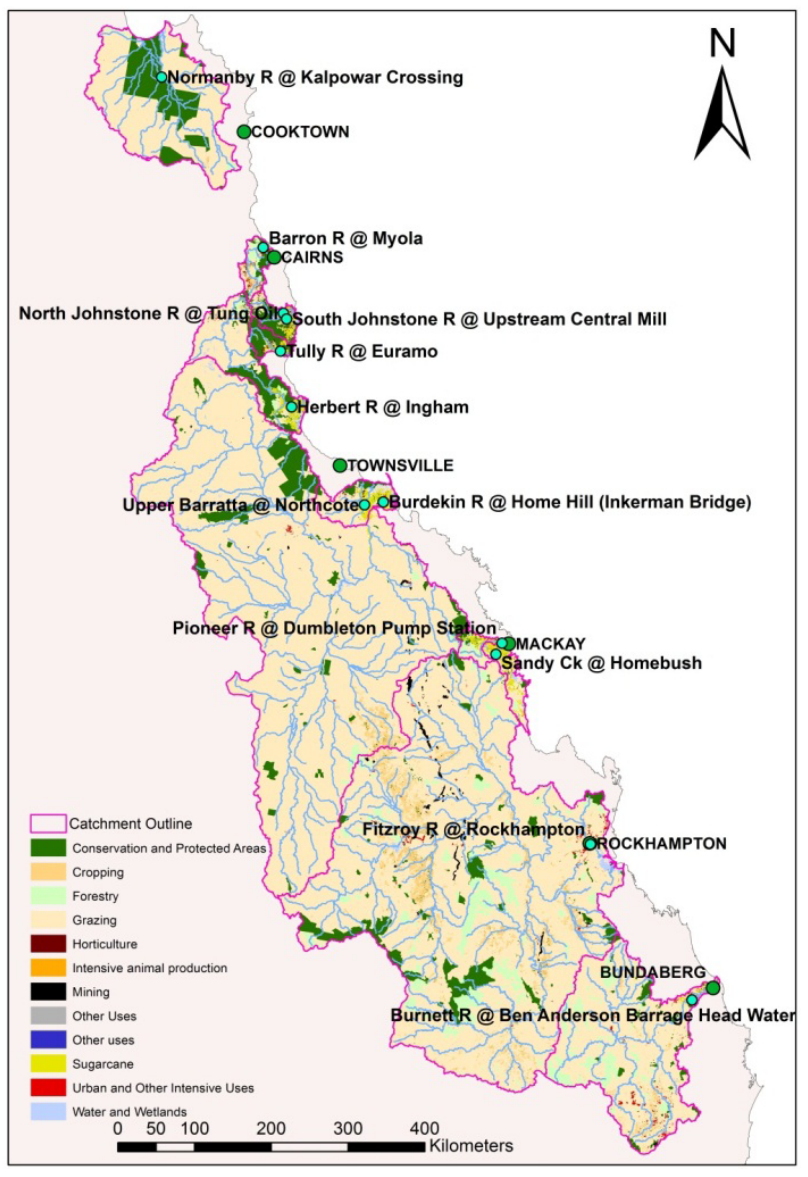

wo methods were used to calculate loads at each site.

Figure 1 Map indicating catchments and the end of system sites (aqua circle)

where the Great Barrier Reef Catchment Loads Monitoring Program is currently monitoring. resulted in more than 250,000 discrete data points for load estimation. The monitoring data suggests more than 126 million tonnes of sediment, approximately 420,000 tonnes of total nitrogen, approximately 47,000 tonnes of dissolved inorganic nitrogen, approximately 130,000 total phosphorus and approximately 21,000 tonnes of dissolved inorganic phosphorus loads being discharged into the GBR lagoon between 2006 and 2012. The 12 end-of system sampling locations can be seen in Figure 1.

\section{LOAD ESTIMATION AND MODEL VALIDATION}

Load estimates were calculated using the Loads Tool from Water Quality Analyser 2.1.1.0 (eWater 2011). Annual loads were estimated for total suspended solids (TSS) and nutrients, including total nitrogen (TN), particulate nitrogen (PN), dissolved organic nitrogen (DON), dissolved inorganic nitrogen (DIN), total phosphorus (TP), particulate phosphorus (PP), dissolved inorganic phosphorus (DIP), and dissolved organic phosphorus (DOP). Annual pesticide loads were also estimated for ametryn, atrazine, diuron, hexazinone and tebuthiuron. Annual and daily load estimates were derived. Daily loads are not presented in this paper. One of Beale ratio (equation 2 ) were applied:

$$
\text { Load }=\sum_{j=1}^{n} \frac{c_{j}+c_{j+1}}{2} \times q_{j}
$$

where $c_{j}$ is the $j^{\text {th }}$ sample concentration, and $q_{j}$ is the inter-sample mean flow (eWater 2011). For the Beale ratio method (Equation 2):

$$
\text { Load }=Q\left(\frac{\bar{l}}{\bar{q}}\right)\left\{\frac{1+\frac{1}{N} \frac{\rho \sigma L \sigma Q}{\bar{l} \bar{q}}}{1+\frac{1}{N} \frac{\sigma^{2} Q}{q^{2}}}\right\}
$$

where $Q$ is the total discharge for the period, $\bar{l}$ is the average load for a sample, $L$ is the observed load, $\bar{q}$ is the average of $\mathrm{N}$ discharge measurements, $\sigma$ is the standard error of $L$ and $\rho$ is the correlation coefficient for $L$ and $Q$ (eWater 2011).

For the purpose of comparison between years, the annual loads were normalised to take into account differences in annual river discharge. This was done by applying equation 3 :

$$
A A N L=\frac{L}{Q} \times q
$$

where AANL is the annual average normalised loads, L is the estimated annual loads, Q is the total annual discharge and $\mathrm{q}$ is the mean annual average discharge over the period for which flow records were available at each gauging station. 
The GBRCLMP load estimates were then used to validate the modelled catchment loads (Dougall \& Carroll 2013) at the same monitoring locations. For the next phase of Reef Plan 2013 the catchment models will be used to assist in prioritising the location of monitoring sites to improve model load estimations.

\subsection{Annual average normalised loads}

The annual average normalised loads were calculated on monitoring data from 1 July 2006 to 30 June 2012. During this period the monitored catchments went from strong El Niño to a strong La Nina weather patterns. Most of the GBR catchments were drought declared (prior to 2009) and in 2008-2009 the drought broke and the catchments experienced some of the highest rainfall ever recorded. This data set has given a unique snapshot of pollutant loads during extreme climatic conditions. For the purpose of this paper, the loads presented (Figure 3) for each year have been normalised to the long-term annual average flow to remove the effect of extreme dry and wet climatic conditions.

During 2006-2012, the monitored catchments (with a combined surface area of approximately $330,000 \mathrm{~km}^{2}$ ) generated an average annual normalised load of approximately 5.8 million tonnes ( $t$ ) of TSS, 23,000 t of TN, and 6,200 t of TP. The Fitzroy and Burdekin catchments combined, representing 78 per cent (\%) of the monitored catchment area, contributed the majority of the annual average normalised loads of TSS and nutrients including $77 \%$ of TSS (approximately 4.5 million t), $56 \%$ of TN (approximately 13,600 t) and $75 \%$ of TP (approximately $3500 \mathrm{t}$ ) (Figure 2 ).

Figure 2 Load and per cent contribution of each catchment to the combined averaged normalised loads for 2009 to 2012 , including total suspended

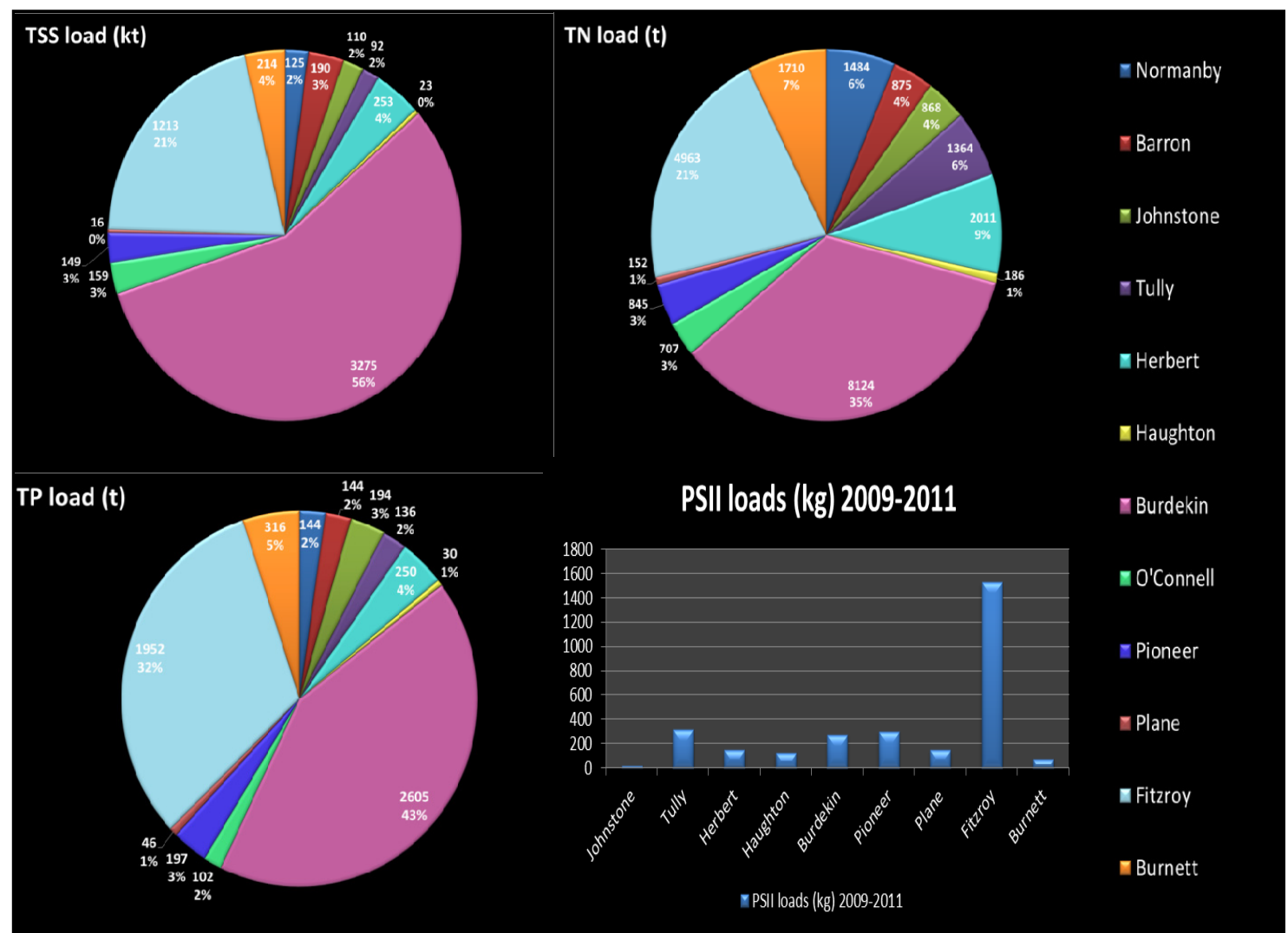

solids, total nitrogen, total phosphorus, and photosystem II inhibiting herbicides

Pesticides were only monitored from 2009 in the Johnstone, Tully, Herbert, Haughton, Burdekin, Pioneer, Plane, Fitzroy and Burnett catchments. The Fitzroy had the largest annual average normalised load for the five photosystem II inhibitor (PSII) herbicides - (ametryn, atrazine, diuron, hexazinone and tebuthiuron) and was approximately 1500 kilograms (kg). The Tully, Pioneer and Burdekin generated approximately 320, 300, $270 \mathrm{~kg}$ of PSII pesticides, respectively). The remaining catchments generated average annual normalised loads ranging from 145 to $20 \mathrm{~kg}$. Based on a regional perspective the Fitzroy River delivers over $50 \%$ of the total monitored annual average normalised pesticide load to the GBR lagoon. The two sugarcane dominant 
regions (Mackay Whitsundays and Wet Tropics) deliver approximately 33\% with the Burdekin and Burnett region delivering $17 \%$ of the average annual normalised PSII herbicide load.

\subsection{Annual normalised total suspended solid loads}

Annual normalised TSS loads for each end-of-system sites were calculated for the years from 2006 to 2012 (see Figure 3). As the monitoring program has evolved through the years, certain catchments were not monitored for various reasons. The Herbert catchment was not monitored between June 2007 and July 2009. Both the Haughton and Plane catchments were not monitored between June 2006 and July 2009. The O'Connell catchment was not monitored between June 2009 and July 2012. No discharge occurred in the Burnet catchment between June 2006 and July 2008 and therefore the TSS load is reported as less than $1 \mathrm{kt}$.

In general, the normalised TSS loads are variable over the period (see Figure 3) even though the loads have been normalised by flow. Modelling is required to remove climatic variation from the data to clearly inform land management investment and outcomes. Since the drought broke in 2009 and groundcover has improved the normalised TSS loads have declined (Figure 3).

Figure 3 Annual normalised total suspended solids loads (kt) for 2009 to 2012

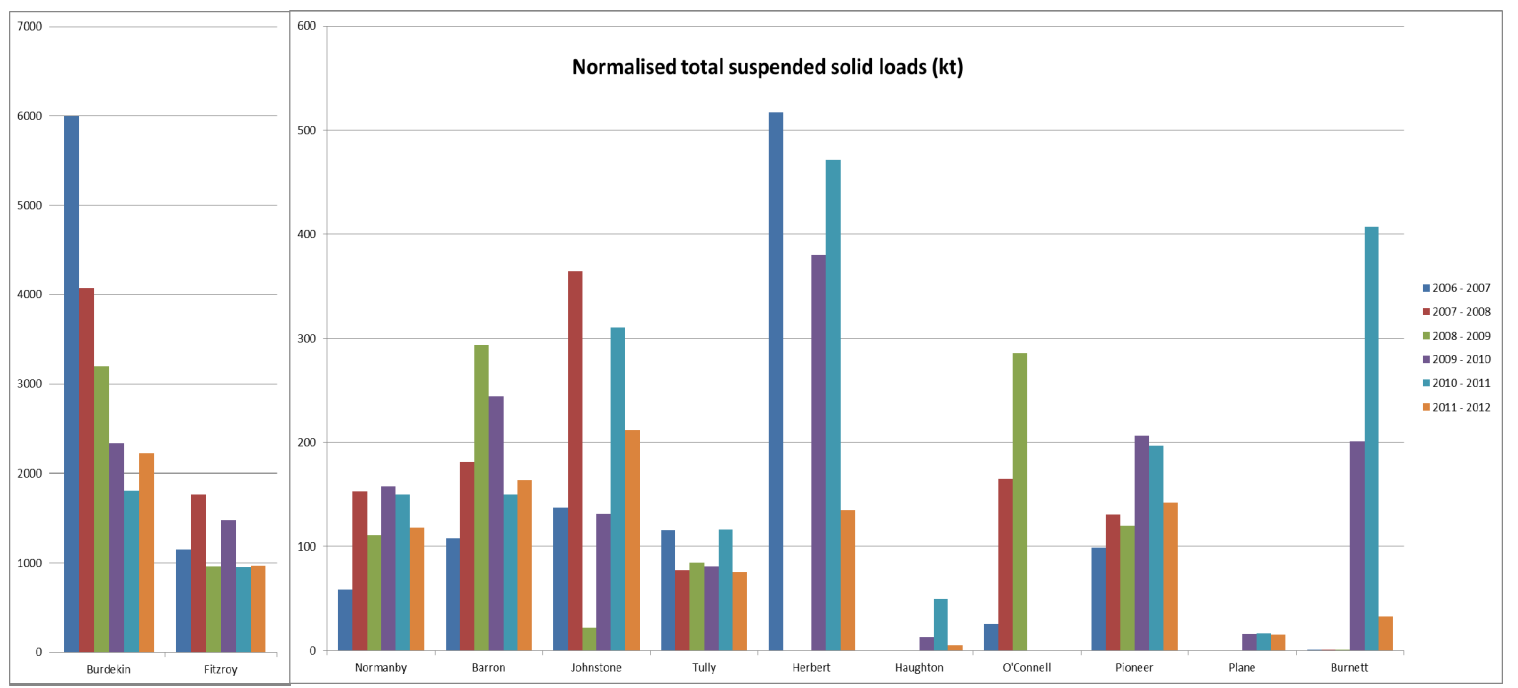

5. SAMPLING REPRESENTIVITY AND SAMPLING DESIGN

The suitability of the TSS and nutrient sampling data for load estimation was assessed using the method of Turner et al. (2012 and 2013). The data were assessed against two criteria: (1) the number of samples collected in the top five \% of the flow event; and (2) the ratio between the highest flow rate sampled and the maximum flow rate recorded. Currently for Pesticides, there is no similar quality scoring method developed. The representivity was determined by assigning a score using the system presented in Table 1.

Table 1 Scores assigned to total suspended solids and nutrients data to rate their representivity.

\begin{tabular}{|c|c|c|c|}
\hline $\begin{array}{c}\text { Number of samples in top 5 per } \\
\text { cent of flow }\end{array}$ & Score & $\begin{array}{c}\text { Ratio of highest flow sampled to } \\
\text { maximum flow recorded }\end{array}$ & Score \\
\hline $0-9$ & 1 & $0.0-0.19$ & 1 \\
\hline $10-19$ & 2 & $0.2-0.39$ & 2 \\
\hline $20-29$ & 3 & $0.4-0.59$ & 3 \\
\hline $30-39$ & 4 & $0.6-0.79$ & 4 \\
\hline$>40$ & 5 & $>0.8$ & 5 \\
\hline
\end{tabular}

The rating of sample representivity for each monitoring site was the sum of the scores for the two criteria. Sample representivity was rated as: "excellent" when the total score was greater than or equal to eight; "good" when the total score was six or seven; "moderate" for total scores of four or five or "indicative" when the score was less than four out of ten.

The average representivity of all the data from 2006 to 2012 was six "good". Since 2009 the average representivity of the data increased to seven. The design of the GBRCLMP changed in 2009 with enhanced sampling protocols that improved the robustness of load estimates. To assess the effectiveness of the changed 
design the number of sites that achieved an 'excellent' sampling representativity before and after 2009 was determined. Before 2009 only 11 sites had excellent representivity, however since 2009, 22 sites have achieved excellent representivity, a marked improvement.

Future improvements to the program will look into real-time telemetry in-situ turbidity and nitrate probes as well as Acoustic Doppler Current Profilers (ADCPs) to determine real-time sediment loads.

\section{THE SAMPLING REGIME DETERMINES THE MOST APPROPRIATE LOAD ESTIMATION METHOD}

In 2009, Marsh and Waters (2009) estimated that there were 38 different methods to estimate pollutant loads. However the calculated loads from each method can vary by orders of magnitude, particularly when events are poorly sampled. It is essential that reliable estimates of pollutant loads are calculated from well sampled monitoring data in order to validate catchment models.

Marsh (2011) investigated and recommended implementation of a framework for selecting the most appropriate load estimation method, based on the sampling regime and distribution of samples across an event.

Thomson et al (2011) designed such a framework based on monitoring data from the GBRCLMP and the related South East Queensland Event Monitoring Program. This framework selects the best loads estimation method for TSS, TN, TP, oxidised nitrogen, ammonium, and DIP based on the sampling regime (sample size and sample distribution) for sites.

Thomson et al (2011) showed that there was a relationship between the sampling regime and the error in loads estimation. The greatest error in load estimations occurred when sampling was not undertaken on the fall of the hydrograph. It was also recommended that samples, whenever practical, be collected across both the rise and fall of the hydrograph. Furthermore, it was recommended that for Great Barrier Reef catchments at least six samples be collected, with most on the fall, to reduce the error to approximately $20 \%$. Increasing the sample size beyond these recommended minima (6) while maintaining an even distribution of samples over the hydrograph, further decreases the error towards $10 \%$ (Thomson et al 2011). It also showed that there was no single load calculation method that was better than the others. Rather, it found that the best method varied by site (GBR vs. South East Queensland) and sampling regime.

\section{CONCLUSIONS AND FUTURE RECOMENDATION}

Catchment load monitoring is an important component of modelling to validate catchment models and in turn modelling is important to prioritise future monitoring activities. In the new phase of Reef Plan 2013 the GBRCLMP the monitoring program will look to continually improve. This will be achieved through the monitoring, evaluation, reporting and regular assessment of monitoring sites and model requirements. Improving temporal resolution (decreasing load uncertainty) through smart automated sampling, real-time telemetry and new innovative in-situ probes will also be a priority. There is no one solution; rather it will take a multi-disciplinary approach to make sure that the monitoring is of a high standard and it is the point of truth to validate loads predicted by Source Catchment models.

\section{ACKNOWLEDGMENTS}

The Program is grateful to the Queensland Government hydrographers who were responsible for the installation and maintenance of all gauging stations and associated infrastructure, and for the collection and validation of flow data that are critical to the load estimations presented in this paper. The program is funded by the Queensland Government. The authors wish to thank all stakeholders who assisted in the collection of water samples since 2006. The Program would like to acknowledge assistance and advice provided by the Science Delivery Chemistry Centre and Queensland Health Forensic Scientific Services.

\section{REFERENCES}

DPC (Department of Premier and Cabinet) (2011). Reef Water Quality Protection Plan - First Report 2009 Baseline.

Reef Water Quality Protection Plan Secretariat, Brisbane, Australia

Carroll, C., D. Waters, R.Ellis, K.McCosker, M.Gongora , C.Chinn, K.Gale (2013) Great Barrier Reef Paddock to Reef

Monitoring \& Modeling Program Modsim 2013, Adelaide SA. 
Turner et al., Monitoring to enhance modelling - A loads monitoring program for validation of catchment models

Dougall, C., Waters, D. (2013). Source Catchments Modeling in Great Barrier Reef Catchments: Facilitating model improvement through Event based Water quality and quantity assessment. Modsim 2013, Adelaide SA.

eWater Cooperative Research Centre (2011). Water Quality Analyser v2.0.0 User Guide. eWater Cooperative Research Centre, Canberra, Australia.

Eyre B. (1998). Transport, retention and transformation of material in Australian estuaries. Estuaries, 21(4A): 540-551.

Joo M., Raymond M., McNeil V., Huggins R., Turner R., Choy S. (2012). Estimates of sediment and nutrient loads in 10 major catchments draining to the Great Barrier Reef during 2006-2009. Marine Pollution Bulletin, 65(4-9):150-166.

Kroon F., Kuhnert P., Henderson B., Henderson A., Turner R., Huggins R., Wilkinson S., Abbot B., Brodie J., Joo M. (2010). Baseline pollutant loads to the Great Barrier Reef. CSIRO: Water for a Healthy Country Flagship Report series, Australia.

Marsh N. and Waters D. (2009). Comparison of load estimation techniques and their associated error. Proceedings of 18th World IMACS/MODSIM Congress. Cairns, Australia. <http://www.mssanz.org.au/modsim09/I4/marsh_I4.pdf $>$

Marsh N. (2011). Estimating mass loads in tropical and subtropical streams: a comparison of sampling and load estimation methods - Technical report, prepared for Department of Environment and Resource Management, Brisbane, Australia.

Nicholls N. (1988). El Niño and rainfall variability. Journal of Climate, 1:418-442.

Shaw M., Dunlop J., McGregor G. (2011). Identifying pesticides and locations for monitoring in the Great Barrier Reef Catchments: approach and assessment outputs. Catchment Water Sciences and Water Planning Ecology, Environment and Resource Sciences, Department of Environment and Resource Management, Brisbane, Queensland. pp. 86.

Smith R., Middlebrook R., Turner R., Huggins R., Vardy S., Warne M.St.J. (2012). Large-scale pesticide monitoring across Great Barrier Reef catchments - Paddock to Reef Integrated Monitoring, Modelling and Reporting Program. Marine Pollution Bulletin, 65(4-9):117-127.

The State of Queensland (2013a). 2013 Scientific Consensus Statement: Land use impacts on Great Barrier Reef water quality and ecosystem condition. Published by the Reef Water Quality Protection Plan Secretariat, July 2013, Brisbane Queensland, 4000.

The State of Queensland (2013b). Reef Water Quality Protection Plan 2013 Securing the health and resilience of the Great Barrier Reef World Heritage Area and adjacent catchments. Published by the Reef Water Quality Protection Plan Secretariat, July 2013. Brisbane Queensland, 4000.

Thomson B., Rogers B., Dunlop J., Ferguson B., Marsh N., Vardy S.,Warne, M.St.J. (2012). A framework for selecting the most appropriate load estimation method for events based on sampling regime. 1Water Quality and Investigations, Environmental Monitoring and Assessment Science, DSITIA, Brisbane, 56p

Turner R., Huggins R., Wallace R., Smith R., Vardy S., Warne M.St.J. (2012). Sediment, Nutrient and Pesticide Loads: Great Barrier Reef Catchment Loads Monitoring 2009-2010. DSITIA, Brisbane.

Turner R., Huggins R., Wallace R., Smith R., Warne M St.J. (2013). Total suspended solids, nutrient and pesticide loads (2010-2011) for rivers that discharge to the Great Barrier Reef Great Barrier Reef Catchment Loads Monitoring 20102011 Department of Science, Information Technology, Innovation and the Arts, Brisbane.

Wallace R., Turner R., Huggins R., Smith R., Warne M St.J. (2013). Total suspended solids, nutrient and pesticide loads (2011 -2012) for rivers that discharge to the Great Barrier Reef Great Barrier Reef Catchment Loads Monitoring 20112012 Department of Science, Information Technology, Innovation and the Arts, Brisbane. 